\title{
Blossoming contusions: identifying factors contributing to the expansion of traumatic intracerebral hemorrhage
}

\author{
Joseph A. Carnevale, MD, ${ }^{1}$ David J. Segar, MD,,2 Andrew Y. Powers, BA, ${ }^{1}$ Meghal Shah, BS, ${ }^{1}$ \\ Cody Doberstein, BS, ${ }^{4}$ Benjamin Drapcho, BA, ${ }^{1}$ John F. Morrison, MD, ${ }^{3}$ John R. Williams, MD, ${ }^{1,5}$ \\ Scott Collins, RT(R)(CT), ${ }^{6}$ Kristina Monteiro, PhD, ${ }^{1}$ and Wael F. Asaad, MD, PhD ${ }^{1,7}$
}

\begin{abstract}
1Department of Neurosurgery, Warren Alpert Medical School of Brown University, Providence, Rhode Island; '2Department of Neurosurgery, Brigham and Women's Hospital, Boston, Massachusetts; ${ }^{3}$ Department of Neurosurgery, University at Buffalo, New York; ${ }^{4}$ Haverford College, Haverford, Pennsylvania; ${ }^{5}$ Department of Neurological Surgery, University of Washington, Seattle, Washington; and ${ }^{6}$ Department of Diagnostic Imaging and ${ }^{7}$ Norman Prince Neurosciences Institute, Rhode Island Hospital, Providence, Rhode Island
\end{abstract}

OBJECTIVE Traumatic brain injury (TBI) remains a significant cause of neurological morbidity and mortality. Each year, more than 1.7 million patients present to the emergency department with TBI. The goal of this study was to evaluate the prognosis of traumatic cerebral intraparenchymal hemorrhage (tIPH), to develop subclassifications of these injuries that relate to prognosis, and to provide a more comprehensive assessment of hemorrhagic progression contusion (HPC) by analyzing the rate at which tIPH "blossom" (i.e., expansion), depending on a variety of intrinsic and modifiable factors.

METHODS In this retrospective study, 726 patients (age range 0-100 years) were admitted to a level 1 trauma center with tIPH during an 8-year period (2005-2013). Of these patients, 491 underwent both admission and follow-up head CT (HCT) within 72 hours. The change in tIPH volume over time, the expansion rate, was recorded for all 491 patients. Effects of prehospital and in-hospital variables were examined using ordinal response logistic regression analyses. These variables were further examined using multivariate linear regression analysis to accurately predict the extent to which a hemorrhage will progress.

RESULTS Of the 491 (67.6\%) patients who underwent both admission and follow-up HCT, 368 (74.9\%) patients experienced HPC. These hemorrhages expanded on average by $61.6 \%(4.76 \mathrm{ml})$ with an average expansion rate of $0.71 \mathrm{ml}$ per hour. On univariate analysis, certain patient characteristics were significantly $(p<0.05)$ related to HPC, including age (> 60 years), admission Glasgow Coma Scale score, blood alcohol level, international normalized ratio, absolute platelet count, transfusion of platelets, concomitant anticoagulation and antiplatelet medication, the initial tIPH volume on admission $\mathrm{HCT}$, and ventriculostomy. Increased expansion rate was significantly associated with patient disposition to hospice or death $(p<0.001)$. To determine which factors most accurately predict overall patient disposition, an ordinal-response logistic regression identified systolic blood pressure, Injury Severity Score, admission Glasgow Coma Scale score, follow-up scan volume, transfusion of platelets, and ventriculostomy as predictors of patient discharge disposition following tIPH. A multivariate logistic regression identified several prehospital and in-hospital variables (age, Injury Severity Score, blood alcohol level, initial scan volume, concomitant epidural hematoma, presence of subarachnoid hemorrhage, transfusion of platelets, and ventriculostomy) that predicted the volumetric expansion of tIPH. Among these variables, the admission tIPH volume by HCT proved to be the factor most predictive of HPC.

CONCLUSIONS Several factors contribute to the rate at which traumatic cerebral contusions blossom in the acute posttraumatic period. Identifying the intrinsic and modifiable aspects of cerebral contusions can help predict the rate of expansion and highlight potential therapeutic interventions to improve TBI-associated morbidity and mortality.

https://thejns.org/doi/abs/10.3171/2017.7.JNS17988

KEY WORDS intraparenchymal hemorrhage; traumatic brain injury; hemorrhagic progression of contusion; volumetric progression; intracerebral hemorrhage; trauma

\footnotetext{
ABBREVIATIONS AIC = Akaike information criterion; $\mathrm{BAL}=$ blood alcohol level; $\mathrm{EDH}=$ epidural hematoma; $\mathrm{GCS}=\mathrm{Glasgow}$ Coma Scale; $\mathrm{HCT}=$ head CT; HPC = hemorrhagic progression of contusion; INR = international normalized ratio; ISS = Injury Severity Score; NISS = New Injury Severity Score; SAH = subarachnoid hemorrhage; $\mathrm{SBP}=$ systolic blood pressure; $\mathrm{SDH}=$ subdural hematoma; $\mathrm{TBI}=$ traumatic brain injury; tIPH = traumatic intraparenchymal hemorrhage.

SUBMITTED April 29, 2017. ACCEPTED July 6, 2017.
}

INCLUDE WHEN CITING Published online January 5, 2018; DOI: 10.3171/2017.7.JNS17988. 
$\mathrm{T}$ HROUGHOUT the world, traumatic brain injury (TBI) remains a significant cause of neurological morbidity and mortality. ${ }^{35,36}$ Annually in the United States, an estimated 1.7 million people experience TBI, resulting in 1.4 million emergency department visits, 270,000 hospitalizations, and 53,000 deaths. Moreover, nearly 5.3 million people live with disability due to TBI (http://www. uab.edu/medicine/tbi/uab-tbi-information-network/bimsinfosheets). ${ }^{3,10,23,31}$ The most common mass lesions associated with TBI are hematomas and contusions, which occur in $13 \%-35 \%$ of patients following TBI. ${ }^{4,6,15,24,37}$ Traumatic contusions, or traumatic intraparenchymal hemorrhages (tIPH), are a type of TBI that can lead to lifelong cognitive, physical, and psychological disability.

Hemorrhagic progression of contusion (HPC) is a potential complication of tIPH and is defined as an increase in hemorrhage volume over time. . $^{1,7,25,32,39}$ HPC can be described as an initial 3D expansion followed by either reduction in volume or further expansion. ${ }^{6,22} \mathrm{HPC}$, which occurs in the first few hours after head trauma, has been demonstrated in 38\%-63\% of TBI patients. Studies investigating HPC have identified initial size of injury, coagulopathy, age, sex, and concurrent noncontusion TBI as the clinical variables correlated with HPC.,32 In one of the largest tIPH cohorts, Cepeda and colleagues identified 782 patients and found a correlation between HPC and multiple contusions, smaller initial volume, acute subdural hematoma (SDH), cisternal compression, older patient age, hypoxia, falls, and decompressive craniectomy. ${ }^{6}$ However, large multivariable studies with volumetrically measured TBI are sparse, and no such study examining the various clinical influences on rates of volumetric hemorrhage expansion has previously been performed. ${ }^{35}$

Currently, there is no standardized protocol for the identification of HPC and its risk factors, clinical course, prognosis, and management. The aim of this retrospective study is to provide a more comprehensive assessment of HPC by analyzing the rate at which tIPHs evolve as a function of relevant prehospital and in-hospital clinical factors. Additionally, we aim to describe correlations between clinical variables and HPC in a population of consecutive TBI patients presenting to a level 1 trauma center. Finally, we aim to use such variables to predict the extent to which a hemorrhage will progress and to describe the prognostic significance of HPC by investigating its relationship to patient outcome.

\section{Methods}

\section{Patient Population and Demographics}

After obtaining institutional review board approval, we conducted a retrospective observational study of all patients with tIPH who presented to the emergency department at Rhode Island Hospital, a level 1 trauma center in Providence, Rhode Island, during an 8-year period (January 2005 to December 2013). A standardized data collection spreadsheet was used, allowing trauma service clinicians to record multiple demographic and clinical variables for each patient (https://www.lifespan.org/ centers-services/trauma-center-rhode-island-hospital/ trauma-patient-registry). From the initial population of 726 consecutive tIPH patients presenting to our trauma center, we excluded all patients from our expansion analysis who did not undergo follow-up head CT (HCT) imaging within 72 hours after injury. After application of exclusion criteria, $491 \mathrm{tIPH}$ patients remained, with admission and follow-up axial HCT scans obtained within 72 hours of injury.

Demographic and clinical data included the following: age, sex, admission systolic blood pressure (SBP), mechanism of injury (fall, motor vehicle collision, or assault and other), presenting Glasgow Coma Scale (GCS) score, Injury Severity Score (ISS), New Injury Severity Score (NISS), blood alcohol level (BAL), international normalized ratio (INR), absolute platelet count, contusion size at admission, time to first HCT, time between HCT sessions, additional intracranial hemorrhage (epidural hematoma [EDH], subarachnoid hemorrhage [SAH], or subdural hematoma [SDH]), medical interventions and procedures (use of anticoagulation/antiplatelet medication, platelet transfusion, craniotomy or craniectomy, or ventriculostomy), and discharge disposition (home, skilled nursing facility, or death/ hospice). The distribution based on age and sex of our tIPH study population is shown in Fig. 1.

\section{Imaging Analysis}

The rate of HPC was calculated as the difference in volume between the first and second HCT scans divided by the time between the scans. Presence of tIPH was confirmed by both junior and attending radiologists, emergency physicians, and neurosurgeons. We used General Electric 3D imaging software to calculate the volumes of the cerebral contusions using each 5-mm HCT slice (Fig. 2). Furthermore, the presence of an additional intracerebral hemorrhage, $\mathrm{SDH}, \mathrm{EDH}$, or $\mathrm{SAH}$ was noted.

\section{Statistical Analysis}

Patient prehospital and in-hospital characteristics are given as percentages and means (SD). Distribution of the data was tested using quantile-quantile plots and the Shapiro-Wilk test for normal distribution. All variables were nonnormally distributed, and, therefore, nonparametric tests (Kolmogorov-Smirnov test and Kruskal-Wallis test) were used for analysis. Scatter plots were visually reviewed to find relationships between expansion rate and each clinical variable. Furthermore, multicollinearity testing with Pearson product-moment correlation coefficients was performed to eliminate confounding variables (rho $>0.7$ ).

First, Welch's t-test for equality of variance was used to compare the demographic and clinical differences between patients who underwent repeat HCT in the acute period $(n=491)$ and those who did not $(n=235)$. This was done to determine if patients who underwent repeat brain CT were distinct from patients who did not. For patients who underwent repeat brain $\mathrm{CT}$, univariate comparisons were performed using Welch's 2-tailed t-test to identify demographic and clinical differences between tIPH patients with HPC $(n=367)$ and patients with no contusion expansion $(n=124)$. Levene's test of equality of variances was used to test the assumption of homogeneity of variance between samples for each variable $(\mathrm{F}<0.05)$.

Next, we applied ordinal-response logistic regres- 


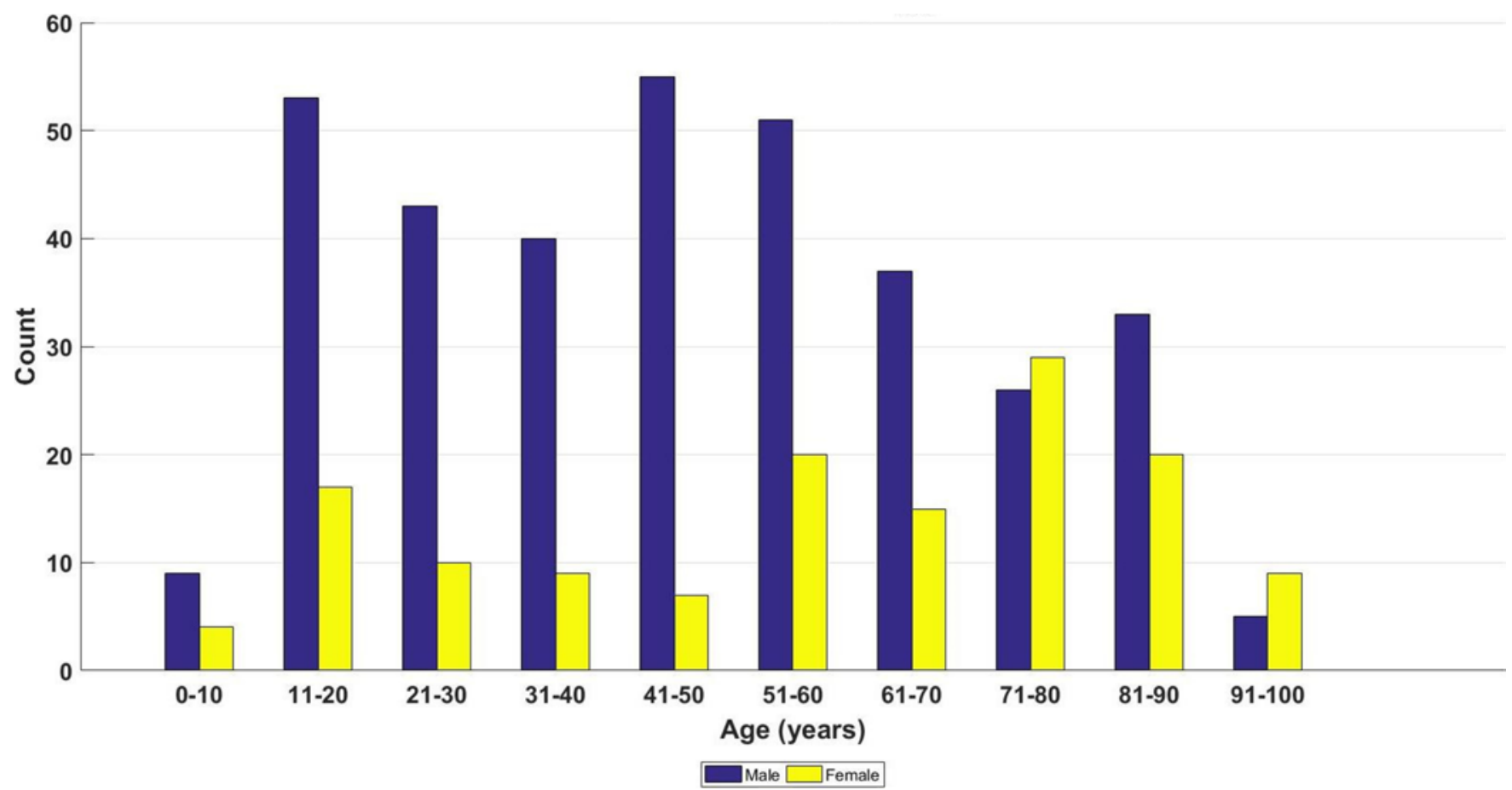

FIG. 1. Histogram showing the age and sex distribution of the tIPH study population.

sion and multiple linear regression to establish predictive models of patient disposition and hemorrhage volume on repeat HCT, respectively. Ordinal-response logistic regression was performed using patient disposition as the dependent variable with categories death/hospice, skilled nursing facility, and home. Sex, age, SBP, ISS, NISS, GCS score, BAL, admission scan volume, follow-up scan volume, time between admission and follow-up scans, presence of $\mathrm{EDH}$, presence of SDH, presence of SAH, platelet transfusion, ventriculostomy, and performance of a craniotomy or craniectomy were used as explanatory variables. Patients missing these data were removed from analysis. The Akaike information criterion (AIC) was used to select the best model. Goodness of fit was evaluated by comparison of expected and actual counts as well as predictive power. Multiple linear regression was performed using the follow-up scan volume as the dependent variable and sex, age, SBP, ISS, NISS, GCS score, BAL, admission scan volume, presence of EDH, presence of SDH, presence of SAH, platelet transfusion, ventriculostomy, and performance of craniotomy or craniectomy as independent variables. Patients missing these data $(n=69)$ were removed from analysis. AIC was again used to select the best model. Goodness of fit was measured by correlation coefficient and residual plot. Model residuals were evaluated both graphically with quantile-quantile plots and by Kolmogorov-Smirnov test for normality.

Statistical analysis used an alpha level of 0.05 with a
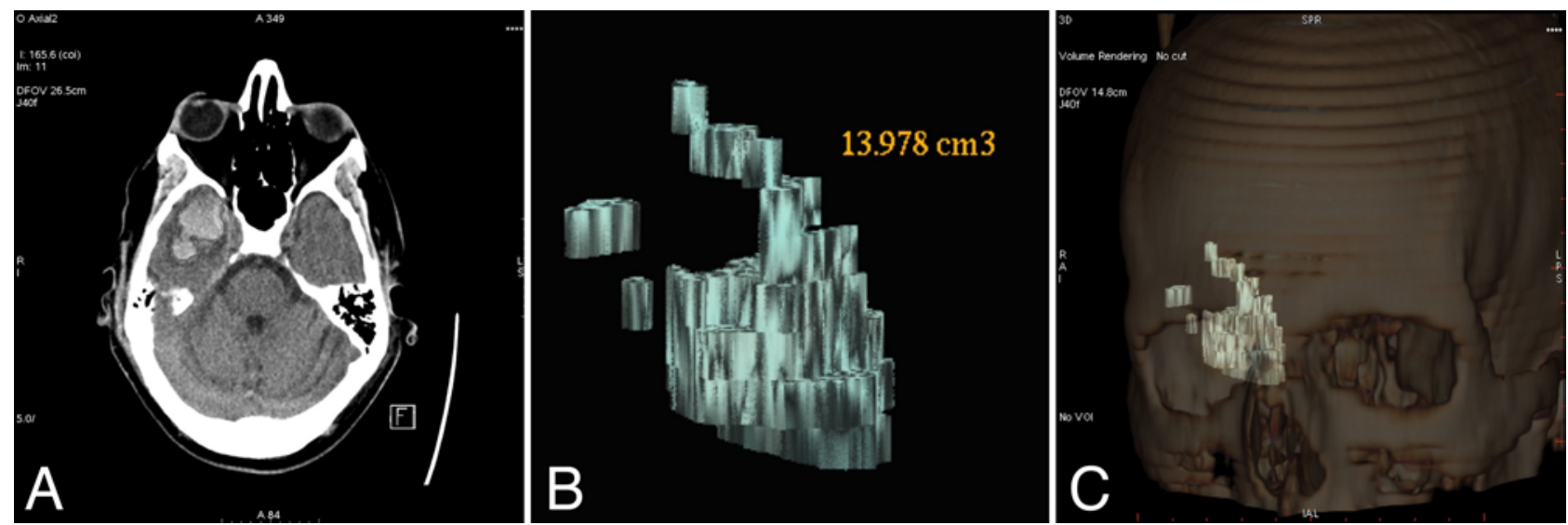

FIG. 2. Volumetric analysis used to calculate volumes of cerebral contusions. A: Noncontrast HCT with tIPH. B: Three-dimensional volumetric model of tIPH. C: Volumetic model of hemorrhage superimposed on the 3D rendering of a patient's skull. 


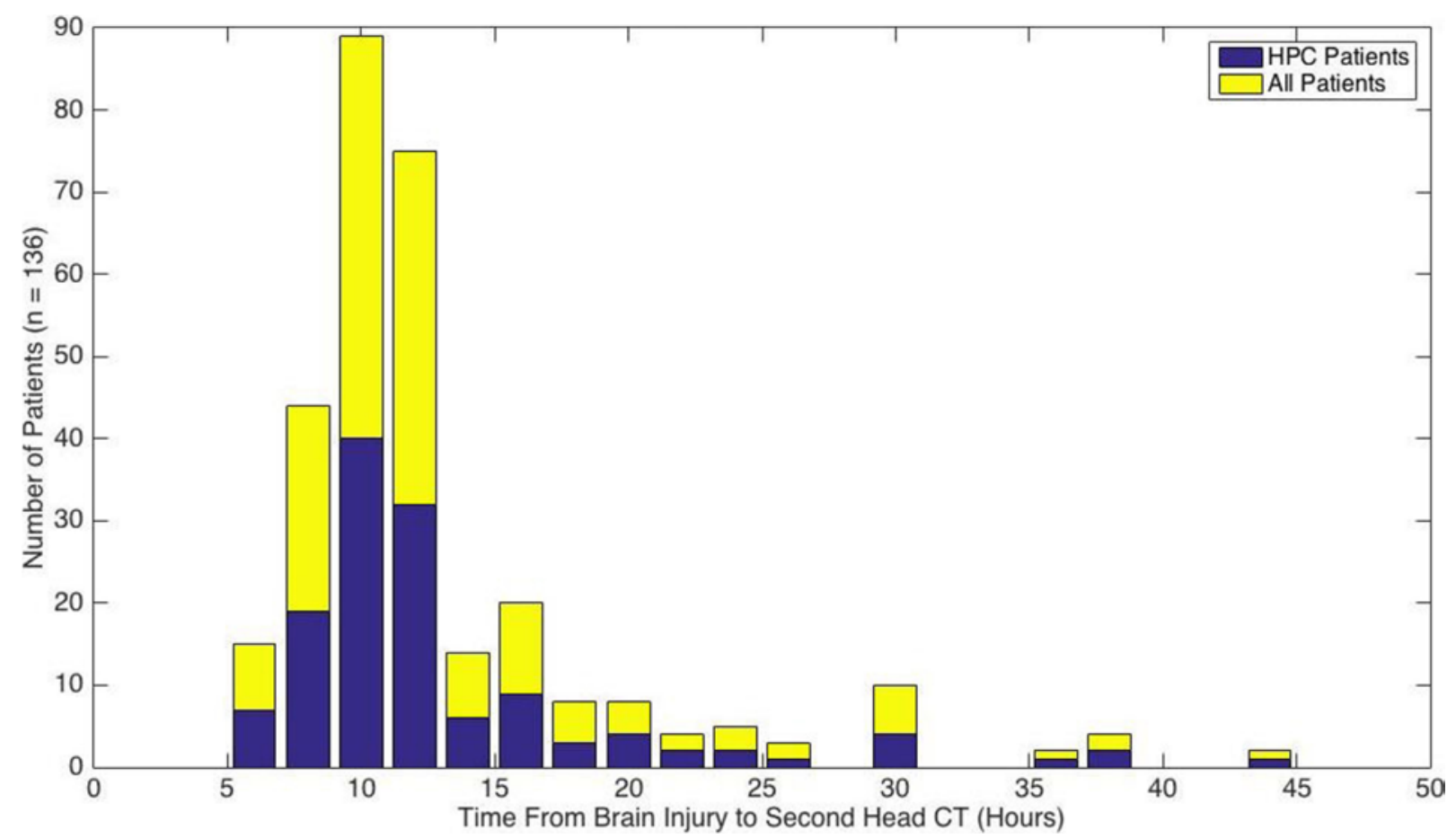

FIG. 3. Graph displaying the difference between HPC patients and the entire population in regard to time (hours) from brain injury to follow-up HCT.

95\% confidence interval. All statistical analyses were performed using MATLAB version r2015a for Macintosh (Mathworks).

\section{Results \\ Study Population}

A total of 726 patients with tIPH were retrospectively reviewed in detail from our database of more than 8412 TBI patients admitted to our level 1 trauma center during an 8-year period. From this cohort, we found that 491 (67.6\%) underwent both admission and follow-up HCT, allowing for assessment of HPC. Of these, 353 (72\%) patients were male and $138(28 \%)$ patients were female. The mean age was 50 years (SD 24), ranging from 0 to 100 years. Type of injury fell into 3 categories: blunt, penetrating, and other; more than $96 \%$ of injuries were blunt. Moreover, the mechanism of injury was separated into more evenly distributed categories: falls $(66 \%)$, motor vehicle collisions (30\%), and assaults and other (4\%). The mean time from injury to admission HCT was 4 hours, while the mean time between first and follow-up HCT was 9 hours. Of the patients with a recorded time of injury, the difference between patients experiencing blossoming (i.e., HPC) and the entire population in regard to time (hours) from brain injury to follow-up HCT is shown in Fig. 3. Of the 491 patients in our analysis, the average admission SBP was $137 \mathrm{~mm} \mathrm{Hg}$, the GCS score was 11.8, the INR was 1.38 , and the absolute platelet count was 130.5 $\times 10^{9} / \mathrm{L}$. Furthermore, $8.3 \%$ of patients received a platelet transfusion, $7.5 \%$ received a craniotomy or craniectomy, $6.9 \%$ received a ventriculostomy, $44.1 \%$ were discharged home, $46.3 \%$ were discharged to a skilled nursing facil- ity, and $9.6 \%$ of patients died. Aside from the 491 patients with follow-up HCT scans, the remaining 235 (32.4\%) patients did not undergo repeat brain imaging following the initial HCT imaging session. The admission data for these 2 groups are compared in Table 1. Comparing the means of these 2 groups, t-tests showed a significant increase in the follow-up HCT population's age $(\mathrm{p}=0.019)$, SBP ( $\mathrm{p}$ $=0.012)$, BAL $(p=0.003)$, presence of EDH $(p<0.001)$, presence of SDH $(p=0.005)$, presence of SAH $(p<0.001)$, ventriculostomy ( $\mathrm{p}<0.001)$, craniotomy or craniectomy $(\mathrm{p}=0.008)$, discharge to home $(\mathrm{p}=0.001)$, and discharge to hospice/death $(\mathrm{p}=0.045)$. Furthermore, $\mathrm{t}$-tests between these 2 groups showed a significant increase regarding discharge to skilled nursing facility in the single HCT group.

\section{Univariate Analysis: HPC Versus No HPC}

Of the 491 patients with an admission and follow-up HCT, tIPH progression occurred in 367 (74.7\%) patients, while no progression occurred in 124 (25.3\%) patients. The admission data for these 2 groups are compared in Table 2. Between these groups, there were no significant differences in demographic and clinical data regarding sex, SBP, BAL, platelet transfusion, time to first HCT imaging session, time between HCT imaging sessions, presence of EDH and SAH, ventriculostomy, craniotomy or craniectomy, and discharge to skilled nursing facility. A nonsignificant commensurate trend was observed between BAL and HPC $(p=0.0587)$. There were significant differences regarding age $(p=0.02)$, ISS $(p=0.004)$, NISS $(p$ $=0.02)$, GCS score $(\mathrm{p}=0.009)$, absolute platelet count $(\mathrm{p}$ $=0.023)$, presence of SDH $(\mathrm{p}=0.05)$, and patient disposition, including discharge to home $(\mathrm{p}=0.01)$ and discharge 
to hospice/death $(\mathrm{p}<0.001)$. Looking closer at patient outcome, the group that was discharged home had a significantly lower proportion of patients who experienced HPC, while the group that was discharged to hospice or died had a significantly higher proportion of patients with HPC.

\section{Univariate Analysis: Expansion Rate}

We reviewed the $491 \mathrm{tIPH}$ patients with both initial and follow-up HCTs from more than 8412 TBI patients admitted to our level 1 trauma center in an 8-year period. The mean expansion rate of tIPH among all patients with HPC was $0.71 \mathrm{ml} / \mathrm{hr}$ (SD 1.8). Continuous variables were categorized using clinically relevant cutoffs. There were significant differences in the expansion rate of tIPH based on age, GCS score, BAL, INR, absolute platelet count, platelet transfusion, use of anticoagulation or antiplatelet medication, initial size of hemorrhage on admission, time between HCT sessions, and ventriculostomy (Table 3). For patient disposition, progression data show a significant difference in expansion rate related to the patient's outcome in the acute setting. Overall, the expansion rate of a patient's hemorrhage was significantly increased in patients who were discharged to hospice or died compared with those who were discharged home in the acute setting.

\section{Multivariate Analysis}

We further evaluated the multivariable interaction of the demographic and clinical characteristics for their ability to predict the outcome and disposition of each patient. Our models address our main hypotheses that HPC is the result of potentially modifiable patient factors, and HPC can impact short-term patient outcomes.

The ordinal-response logistic regression with minimum AIC selected age, SBP, ISS, GCS score, follow-up scan volume, platelet transfusion, and ventriculostomy as predictors of patient disposition following tIPH. Variables from 422 patients were included in this analysis because patients with missing data $(n=69)$ were removed from consideration. Variable coefficients, odds ratios, and $\mathrm{p}$ values for each variable's contribution to likelihood of death/hospice are listed in Table 4. The odds ratios for death/hospice for real-valued variables, including age, SBP, ISS, GCS score, and second scan volume are also shown in Fig. 4. The OR of having medical decline to the point of death or discharge to hospice was 1.073 (95\% CI 1.059-1.088) for each additional year of age; 0.964 (95\% CI 0.921-1.009) for every 5-point increase in SBP; 1.091 (95\% CI 1.059-1.125) and $0.871(95 \% \mathrm{CI} 0.820-0.926)$ for every point increase in ISS and GCS score, respectively; 1.031 (95\% CI 1.0131.049) for each milliliter increase in tIPH volume; 1.802 (95\% CI 0.840-3.866) if the patient underwent a platelet transfusion; and 14.78 (95\% CI 5.452-40.080) if the patient required ventriculostomy.

Next, we analyzed factors influencing the second scan volume of a patient's tIPH given the presenting demographic and clinical characteristics. The linear regression with minimum AIC selected the variables age, NISS, BAL, admission scan volume, presence of EDH, presence of SAH, platelet transfusion, and ventriculostomy as those that collectively predicted the volume on the second scan.
TABLE 1. Comparison of the tIPH population that underwent follow-up HCT versus the population that did not undergo repeat imaging

\begin{tabular}{|c|c|c|c|}
\hline \multirow[b]{2}{*}{ Admission Variable } & \multicolumn{2}{|c|}{ Follow-Up HCT* } & \multirow[b]{2}{*}{$\begin{array}{c}p \\
\text { Value }\end{array}$} \\
\hline & $\begin{array}{c}\text { Yes } \\
(n=491)\end{array}$ & $\begin{array}{c}\text { No } \\
(n=235)\end{array}$ & \\
\hline Age in yrs & 50.3 & 45.2 & $0.019 \dagger$ \\
\hline Male & $72 \%(45 \%)$ & $68 \%(60 \%)$ & 0.302 \\
\hline SBP in $\mathrm{mm} \mathrm{Hg}$ & $137(26.3)$ & $132(26.3)$ & $0.012 \dagger$ \\
\hline ISS & $17.7(9.9)$ & $17.3(10.2)$ & 0.695 \\
\hline NISS & $25.5(13.2)$ & $24.9(14.7)$ & 0.669 \\
\hline GCS score & $11.8(4.4)$ & $12.1(4.6)$ & 0.289 \\
\hline $\mathrm{BAL}$ in $\mathrm{mg} / \mathrm{dl}$ & $61.5(105.5)$ & $38.3(91.4)$ & $0.003 \dagger$ \\
\hline INR & $1.379(1.186)$ & $1.206(0.261)$ & 0.144 \\
\hline Platelet transfusion & $8.3 \%(28 \%)$ & $5.3 \%(22 \%)$ & 0.121 \\
\hline $\begin{array}{l}\text { Time to 1st scan } \\
\text { in hrs }\end{array}$ & $3.9701(3.4)$ & $4.223(3.9)$ & 0.62452 \\
\hline \multicolumn{4}{|l|}{$\begin{array}{l}\text { Additional intracra- } \\
\text { nial bleed }\end{array}$} \\
\hline $\mathrm{EDH}$ & $24.8 \%(44 \%)$ & $13.3 \%(35 \%)$ & $1.273 \times 10^{-4} \dagger$ \\
\hline $\mathrm{SDH}$ & $43.4 \%(50 \%)$ & $32.7 \%(47 \%)$ & $0.005 \dagger$ \\
\hline $\mathrm{SAH}$ & $48.2 \%(50 \%)$ & $32.3 \%(47 \%)$ & $4.4 \times 10^{-5} \dagger$ \\
\hline Craniectomy & $7.5 \%(26 \%)$ & $3.1 \%(17 \%)$ & $0.008 \dagger$ \\
\hline $\begin{array}{l}\text { Use of ventriculos- } \\
\text { tomy }\end{array}$ & $6.9 \%(24 \%)$ & $1.3 \%(10 \%)$ & $5.479 \times 10^{-5} \dagger$ \\
\hline \multicolumn{4}{|l|}{$\begin{array}{l}\text { Discharge disposi- } \\
\text { tion }\end{array}$} \\
\hline Home & $44.1 \%(50 \%)$ & $57.3(50 \%)$ & $0.001 \dagger$ \\
\hline SNF & $46.3 \%(50 \%)$ & $27.6(45 \%)$ & $7.386 \times 10^{-7} \dagger$ \\
\hline Hospice/death & $9.59 \%(29 \%)$ & $15.1(36 \%)$ & 0.045 \\
\hline
\end{tabular}

SNF = skilled nursing facility.

* Values are presented as the mean (SD) unless stated otherwise.

† Significant following Benjamini-Hochberg procedure $(q=0.05, m=18)$.

Patients with missing data $(n=74)$ were again removed from consideration. Variable main effects, multiplicative (i.e., interaction) effects, $p$ values, and correlation coefficients $\left(\right.$ partial $r^{2}$ ) are shown in Table 5. Overall, the regression had a correlation coefficient of 0.529. Multiplicative effects for real-valued variables are shown in Table 5. A quantile-quantile plot of residuals is shown in Fig. 5. The Kolmogorov-Smirnov test for normality did not demonstrate that the model's residuals were nonnormally distributed $(\mathrm{p}=0.447)$.

\section{Discussion}

Many factors contribute to the rate of contusion expansion after TBI. Understanding each individual variable's contribution to this volumetric progression could potentially lead to strategies to improve overall patient outcomes. Because complex interactions of each patient's intrinsic and modifiable presenting characteristics could obscure what combination of factors predict either an idle or rapidly expanding tIPH, we assessed prehospital and in-hospital variables and their relation to expansion rate 
TABLE 2. Comparison of patients with tIPH who experienced HPC and those who did not

\begin{tabular}{|c|c|c|c|}
\hline \multirow[b]{2}{*}{ Admission Characteristics } & \multicolumn{2}{|c|}{$\mathrm{HPC}^{*}$} & \multirow[b]{2}{*}{ p Value } \\
\hline & Yes $(n=367)$ & No $(n=124)$ & \\
\hline Age in yrs & $51.7(588.98)$ & $45.9(628.86)$ & 0.023717 \\
\hline Male & $0.7248(0.20)$ & $0.688(0.21639)$ & 0.44143 \\
\hline SBP in $\mathrm{mm} \mathrm{Hg}$ & $137.42(685.59)$ & $137.07(716.1)$ & 0.90026 \\
\hline ISS & $18.281(112.01)$ & $15.808(54.027)$ & $0.0042625 \dagger$ \\
\hline NISS & $26.305(180.59)$ & $22.983(157.3)$ & 0.015298 \\
\hline GCS score & $11.478(20.747)$ & $12.635(15.216)$ & 0.0090166 \\
\hline $\mathrm{BAL}$ in $\mathrm{mg} / \mathrm{dl}$ & $66.243(12080)$ & $47.424(8161.7)$ & 0.058688 \\
\hline INR $\ddagger$ & $1.4149(1.7697)$ & $1.4632(4.8853)$ & 0.3039 \\
\hline Absolute platelet count in $\times 10^{9} / \mathrm{L} \S$ & $225.4(5776.8)$ & $245.2(6580.5)$ & 0.0260 \\
\hline Platelet transfusion & $0.092643(0.0843)$ & $0.056(0.05329)$ & 0.15369 \\
\hline Time to 1st HCT in hrs & $4.0183(13.04)$ & $3.7932(4.9244)$ & 0.63928 \\
\hline Time btwn HCTs in hrs & $9.2332(69.463)$ & $10.681(98.05)$ & 0.14403 \\
\hline \multicolumn{4}{|l|}{ Additional intracranial bleed } \\
\hline $\mathrm{EDH}$ & $0.25613(0.19105)$ & $0.224(0.17523)$ & 0.46443 \\
\hline $\mathrm{SDH}$ & $0.46049(0.24912)$ & $0.36(0.23226)$ & 0.047253 \\
\hline $\mathrm{SAH}$ & $0.50409(0.25067)$ & $0.416(0.2449)$ & 0.08802 \\
\hline Craniectomy & $0.070845(0.066)$ & $0.088(0.080903)$ & 0.55151 \\
\hline Use of ventriculostomy & $0.076294(0.0707)$ & $0.048(0.046065)$ & 0.23335 \\
\hline \multicolumn{4}{|l|}{ Disposition } \\
\hline Home & $0.4071(0.24203)$ & $0.54032(0.25039)$ & 0.010772 \\
\hline SNF & $0.47268(0.24994)$ & $0.43548(0.24784)$ & 0.47339 \\
\hline Hospice/death & $0.12022(0.10606)$ & $0.024194(0.0238)$ & $1.5184 \times 10^{-5} \dagger$ \\
\hline
\end{tabular}

* Values are presented as the mean (variance).

$\dagger$ Significant following Benjamini-Hochberg procedure $(q=0.05, m=19)$.

$\ddagger$ Available for 252 patients.

$\S$ Available for 485 patients with an overall mean of 230.5 , median of 226 , and standard deviation of $77.74 \times 10^{9} / \mathrm{L}$.

and patient disposition, first through univariate and then through multivariate analyses.

\section{Age and Sex}

Previous multivariate analyses have demonstrated a positive association between age and likelihood of HPC., 2,6,32,42 Our univariate analysis showed a positive relationship between age and tIPH size on follow-up CT (Table 2) and expansion rate (Table 3). Our multivariate analysis also showed a positive relationship between age and odds of a death/hospice disposition (Table 4) as well as age and size of tIPH on follow-up CT (Table 5). Cepeda and colleagues hypothesized that age-associated structural weaknesses in microvasculature might lead to a higher likelihood of HPC. ${ }^{6}$ This explanation is consistent with our findings regarding tIPH expansion rate, patient disposition, and size of tIPH on follow-up CT.

Prior studies have found a correlation between male sex and likelihood of HPC..$^{32}$ Oertel and colleagues hypothesized that this is due to neuroprotective effects of estrogen and progesterone. However, our univariate analysis showed no significant relationship between male sex and tIPH size on follow-up HCT (Table 2) or expansion rate (Table 3). Therefore, our multivariate analysis removed sex from consideration, as it had little independent predictive value for disposition (Table 4) or size of tIPH on follow-up HCT (Table 5).

\section{Systolic Blood Pressure}

In the present study, there was no significant difference in SBP between contusions that expanded and those that did not expand (Table 2), nor was there a significant difference in contusion expansion rate for SBP $<120 \mathrm{~mm}$ $\mathrm{Hg}$ compared with $\mathrm{SBP} \geq 120 \mathrm{~mm} \mathrm{Hg}$ (Table 3). Neither hypotension nor hypertension was found to be a significant predictor of HPC. However, on multivariate analysis, SBP was found to be negatively correlated with patient disposition to hospice or death, highlighting hypotension, identified as a 5-point decrease in SBP, as a contributor to poor patient outcome following tIPH (Table 4).

Of the studies that examined blood pressure in relation to HPC, Chang et al., Yuan et al., and Oertel et al. did not find a significant correlation between blood pressure and progressive hemorrhage or outcomes after injury. ${ }^{7,32,42}$ However, in a 2015 study by Kim et al., patients with HPC had a mean SBP of $134.5 \mathrm{~mm} \mathrm{Hg}$, which was significantly higher than the mean SBP in patients without HPC (119.6 $\mathrm{mm} \mathrm{Hg}){ }^{21}$ As discussed by Oertel et al., it is possible that the management of hypotension with fluid resuscitation could in itself lead to increased bleeding or hemorrhagic progression..$^{32}$ Given the findings of this study as well as the conflicting findings from prior studies, blood pressure may not independently predict HPC or the expansion rate, but it seems to play a role in more severe outcomes as determined by disposition. 
TABLE 3. Univariate analysis of individual prehospital and inhospital variables and the relationship with the ER of tIPH

\begin{tabular}{|c|c|c|c|}
\hline Independent Variable & $\begin{array}{c}\text { No. of } \\
\text { Patients (\%) }\end{array}$ & $\begin{array}{c}\text { ER } \\
(\mathrm{ml} / \mathrm{hr})\end{array}$ & $p$ Value \\
\hline Age in yrs & & & $0.0452^{*}$ \\
\hline$<60$ & $313(63.7)$ & 0.3479 & \\
\hline$\geq 60$ & $178(36.3)$ & 0.6999 & \\
\hline Sex & & & $0.4480^{*}$ \\
\hline Male & 351 & 0.5187 & \\
\hline Female & 140 & 0.3671 & \\
\hline SBP in $\mathrm{mm} \mathrm{Hg}$ & & & $0.8726^{*}$ \\
\hline$<120$ & 120 & 0.7641 & \\
\hline$\geq 120$ & 357 & 0.3882 & \\
\hline $\mathrm{SBP}$ in $\mathrm{mm} \mathrm{Hg}$ & & & $0.8301 \dagger$ \\
\hline$<90$ & 12 & 0.3877 & \\
\hline $91-140$ & 257 & 0.5646 & \\
\hline$>140$ & 208 & 0.3872 & \\
\hline Mechanism of injury & & & $0.6268^{*}$ \\
\hline Fall & 322 & 0.5311 & \\
\hline MVC & 147 & 0.4546 & \\
\hline Assault \& other & 22 & & \\
\hline GCS score & & & $7.5189 \times 10^{-5} \dagger \ddagger$ \\
\hline 13-15 (mild) & 302 & 0.3484 & \\
\hline 9-12 (moderate) & 45 & 0.2385 & \\
\hline 3-8 (severe) & 110 & 0.9331 & \\
\hline BAL in mg/dl & & & $0.0149^{*} \ddagger$ \\
\hline 0 (negative) & 338 & 0.4142 & \\
\hline$>0$ (positive) & 153 & 0.6109 & \\
\hline $\mathrm{BAL}$ in $\mathrm{mg} / \mathrm{dl}$ & & & $0.042 \dagger$ \\
\hline $1-150$ & 53 & 0.4232 & \\
\hline $150-250$ & 54 & 0.7914 & \\
\hline$>250$ & 46 & 0.6153 & \\
\hline INR & & & $0.00738^{*} \ddagger$ \\
\hline$\leq 1.2$ & 189 & 0.2505 & \\
\hline$>1.2$ & 63 & 1.2352 & \\
\hline Absolute platelet count & & & $0.0079 * \ddagger$ \\
\hline$<150$ & 57 & 0.9365 & \\
\hline$\geq 150$ & 428 & 0.42 & \\
\hline Platelet transfusion & & & $0.0016^{*} \ddagger$ \\
\hline Yes & 41 & 0.9417 & \\
\hline No & 450 & 0.4330 & \\
\hline Anticoag/platelet use & & & $0.004 \dagger \ddagger$ \\
\hline None & 461 & 0.3377 & \\
\hline Aggrenox \& Plavix & $1 \& 6$ & 3.5049 & \\
\hline Coumadin \& Dabigatran & $25 \& 1$ & 1.28 & \\
\hline Time to 1 st HCT in mins $\S$ & & & $0.8092^{*}$ \\
\hline$\leq 180$ & 85 & 0.6610 & \\
\hline$>180$ & 88 & 0.3131 & \\
\hline Size at admission in ml & & & $3.0605 \times 10^{-7} \dagger \neq$ \\
\hline$<1$ & 204 & 0.1158 & \\
\hline $1-5$ & 175 & 0.4811 & \\
\hline$>5$ & 112 & 1.1218 & \\
\hline Time btwn HCT in hrs & & & $0.0099^{*} \ddagger$ \\
\hline$<6.5$ & 245 & 0.6079 & \\
\hline$\geq 6.5$ & 246 & 0.3436 & \\
\hline
\end{tabular}

CONTINUED ON PAGE $1311 »$

\section{» CONTINUED FROM PAGE 1310}

TABLE 3. Univariate analysis of individual prehospital and inhospital variables and the relationship with the ER of tIPH

\begin{tabular}{lrcc}
\hline \multicolumn{1}{l}{ Independent Variable } & $\begin{array}{c}\text { No. of } \\
\text { Patients (\%) }\end{array}$ & $\begin{array}{c}\text { ER } \\
(\mathrm{ml} / \mathrm{hr})\end{array}$ & p Value \\
\hline $\begin{array}{l}\text { Craniectomy } \\
\text { Yes }\end{array}$ & 37 & 1.0850 & $0.0803^{*}$ \\
$\quad$ No & 454 & 0.4258 & \\
\hline $\begin{array}{l}\text { Ventriculostomy } \\
\text { Yes }\end{array}$ & 34 & 0.9157 & $0.0066^{*} \ddagger$ \\
$\quad$ No & 457 & 0.4427 & \\
\hline Disposition & & & $6.6847 \times 10^{-12} \dagger \ddagger$ \\
$\quad$ Home & 272 & 0.1469 & \\
$\quad$ SNF & 173 & 0.4958 & \\
$\quad$ Hospice/death & 46 & 2.3417 & \\
\hline
\end{tabular}

Anticoag = anticoagulant; $\mathrm{ER}=$ expansion rate; $\mathrm{MVC}=$ motor vehicle collision. * $p$ value of the Wilcoxon rank-sum test, which tests the null hypothesis that data in $x$ and $y$ are samples from continuous distributions with equal medians, against the alternative that they are not. The test assumes that the 2 samples are independent. $\mathrm{x}$ and $\mathrm{y}$ can have different lengths. This test is equivalent to $\mathrm{a}$ Mann-Whitney U-test.

t $p$ value of the Kruskal-Wallis test, which tests the null hypothesis that the data in each column of the matrix $x$ come from the same distribution. The alternative hypothesis is that not all samples come from the same distribution. $\ddagger$ Significant following Benjamini-Hochberg procedure $(q=0.05, m=17)$. $\S$ Applicable to 173 patients.

\section{Initial Size of Hemorrhage}

Of all presenting clinical variables, the initial hemorrhage volume is perhaps the most clinically informative and prognostically relevant parameter. ${ }^{1,20}$ Many researchers examining HPC have identified initial tIPH volume as proportionally correlated to the amount of hemorrhagic progression, with smaller lesions remaining relatively stable while larger ones are both more likely to progress and grow by larger amounts. ${ }^{1,7,20}$ However, other multivariate analyses found initial hemorrhage volume to be only associated with prognosis and not volumetric progression, while one group's analysis contrarily concluded that HPC was associated with lower initial volume. ${ }^{6,20}$

For our patient population, the initial volume of a pa-

TABLE 4. Ordinal response logistic regression examining patient factors that contribute to the odds that death/hospice will occur given tIPH

\begin{tabular}{lrcc}
\hline \multicolumn{1}{c}{ Variable } & Coefficient & OR $(95 \% \mathrm{Cl})$ & p Value \\
\hline Age $(+1 \mathrm{yr})$ & 0.071 & $1.073(1.059-1.088)$ & $1 \times 10^{-23^{*}}$ \\
\hline SBP $(+5 \mathrm{~mm} \mathrm{Hg})$ & -0.037 & $0.964(0.921-1.009)$ & 0.113 \\
\hline ISS (+1 point) & 0.087 & $1.091(1.059-1.125)$ & $2 \times 10^{-8^{*}}$ \\
\hline GCS score (1 point) & -0.138 & $0.871(0.820-0.926)$ & $1 \times 10^{-5^{*}}$ \\
\hline $\begin{array}{l}\text { Follow-up scan vol } \\
\text { (+1 ml) }\end{array}$ & 0.030 & $1.031(1.013-1.049)$ & $7 \times 10^{-4^{*}}$ \\
\hline $\begin{array}{l}\text { Platelet transfusion } \\
\text { Ventriculostomy }\end{array}$ & 0.589 & $1.802(0.840-3.866)$ & 0.130 \\
\hline * & 2.693 & $14.782(5.452-40.080)$ & $1 \times 10^{-7^{*}}$ \\
\hline
\end{tabular}

* Significant following Benjamini-Hochberg procedure $(q=0.05, m=7)$. 


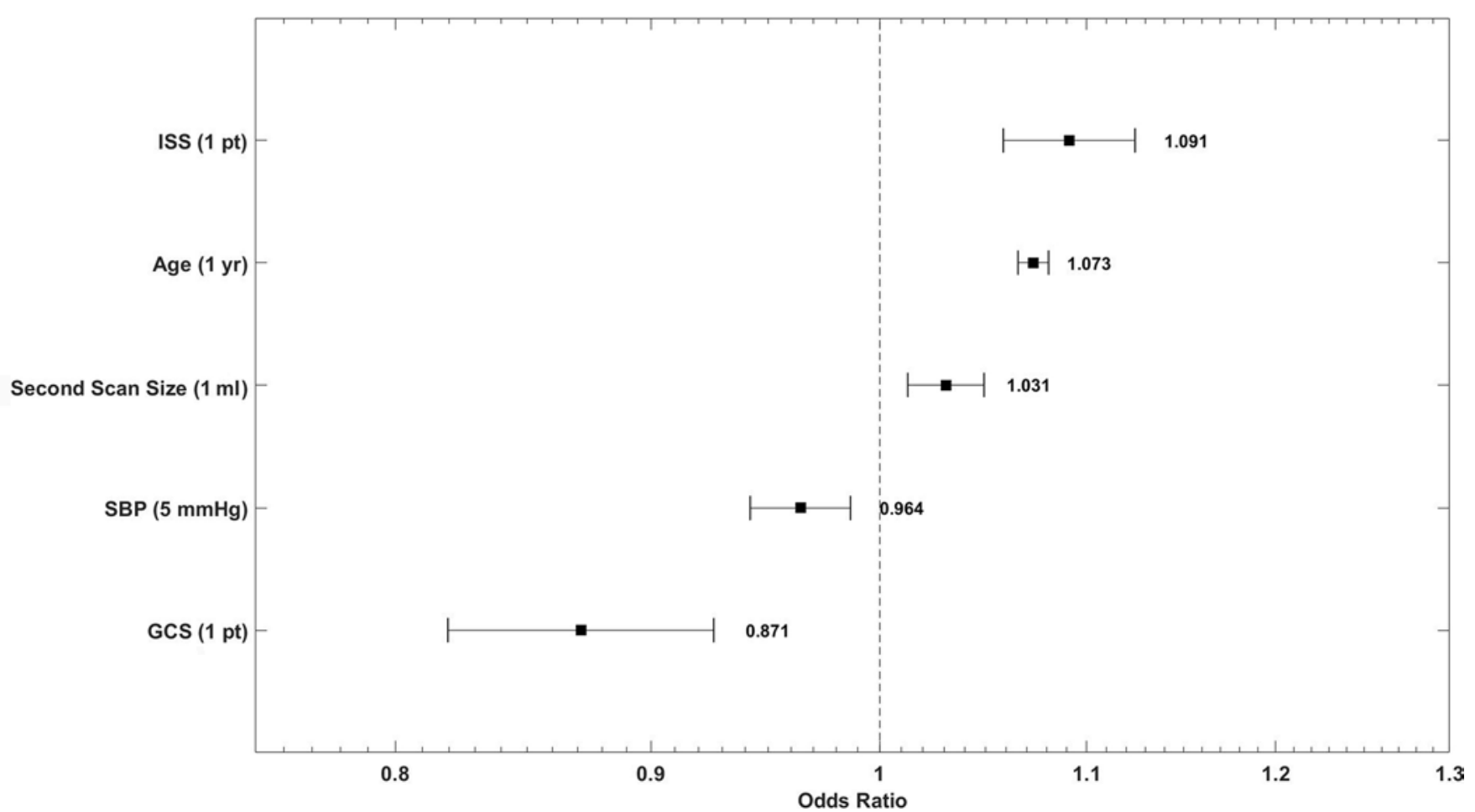

FIG. 4. Odds ratios for death/hospice for real-valued variables, including age, SBP, ISS, GCS score, and second scan volume. Whiskers indicate $95 \% \mathrm{Cl}$. pt = point.

tient's tIPH was found to be predictive of both the rate at which a hemorrhage evolves (Table 3) and the volume of the hemorrhage on repeat HCT (Table 5). ${ }^{5,7}$ Table 3 demonstrates a direct correlation between the initial size of the tIPH and the expansion rate, where larger hemorrhages experience a higher rate of expansion. Furthermore, multivariate analysis identifies initial hemorrhage volume as the greatest predictor of overall expansion, accounting for nearly $31 \%$ of the predictability of hemorrhage size on repeat imaging. Overall, because the initial hemorrhage

TABLE 5. Multiple linear regression to predict volumetric expansion on follow-up HCT

\begin{tabular}{lcccc}
\hline \multicolumn{1}{c}{ Variable } & Coefficient $^{*}$ & $\begin{array}{c}\text { Multiplicative Effect } \\
(95 \% \mathrm{Cl})\end{array}$ & $\begin{array}{c}\mathrm{p} \\
\text { Value } \dagger\end{array}$ & $\begin{array}{c}\text { Partial } \\
\mathrm{r}^{2}\end{array}$ \\
\hline Age $(+1 \mathrm{yr})$ & 0.012 & $1.000(1.000-1.000)$ & $4 \times 10^{-6}$ & 0.051 \\
\hline NISS (+1 point) & 0.022 & $1.023(1.013-1.032)$ & $4 \times 10^{-6}$ & 0.051 \\
\hline BAL (mg/dl) & 0.001 & $1.001(1.000-1.003)$ & 0.005 & 0.019 \\
\hline $\begin{array}{l}\text { Initial scan vol } \\
(+1 \text { ml) }\end{array}$ & 0.079 & $1.082(1.070-1.095)$ & $5 \times 10^{-34}$ & 0.305 \\
\hline $\begin{array}{l}\text { Presence of } \\
\text { EDH }\end{array}$ & 0.317 & $1.373(1.004-1.880)$ & 0.048 & 0.010 \\
\hline $\begin{array}{l}\text { Presence of } \\
\text { SAH }\end{array}$ & 0.424 & $1.529(1.163-2.009)$ & 0.002 & 0.022 \\
\hline $\begin{array}{l}\text { Platelet transfu- } \\
\text { sion }\end{array}$ & 0.629 & $1.876(1.281-2.749)$ & 0.001 & 0.025 \\
\hline \begin{tabular}{l} 
Ventriculostomy \\
\hline
\end{tabular} & 0.702 & $2.017(1.257-3.237)$ & 0.004 & 0.020 \\
\hline
\end{tabular}

* Overall regression of correlation coefficient of 0.529 .

$\dagger$ Significant following Benjamini-Hochberg procedure $(q=0.05, m=8)$. volume is significantly associated with predicting hemorrhage volume on repeat scan and this repeat scan volume is associated with disposition, initial hemorrhage volume can be used as a surrogate not only for the extent of HPC but also for patient outcome. ${ }^{20}$

\section{Injury Scoring}

Current literature presents a muddled picture of the association between GCS scores and HPC and patient outcome. Alahmadi et al. demonstrated that GCS scores at presentation independently predicted the probability of being discharged home. ${ }^{1}$ Additionally, White et al. found that patients with normal or near-normal GCS scores were significantly less likely to experience contusion expansion and that patients with deterioration in their GCS score experienced a 3-fold increase in risk for hemorrhage expansion. ${ }^{41}$ The STICH II (trauma; second Surgical Trial in Lobar Intracerebral Hemorrhage) surgical trial demonstrated that IIPH patients with a good prognosis based on GCS scores of 13-15 can be safely observed and only require craniotomy if their condition deteriorates. ${ }^{29}$ Contrary to these findings, multiple studies found no association between GCS score on admission, subsequent GCS score, or hemorrhage expansion. ${ }^{6,7,13,32,38}$ Juratli et al. noted that about half of their patients who experienced contusion expansion had a GCS score greater than 8 and deteriorated in the next few hours, concluding that use of GCS score alone as a decision-making tool for treatment choice may fail to provide sufficient care. ${ }^{20}$ For our patient population, there was no significant difference in admission GCS score between patients who underwent repeat HCT and those who did not, which suggests that this neurological 


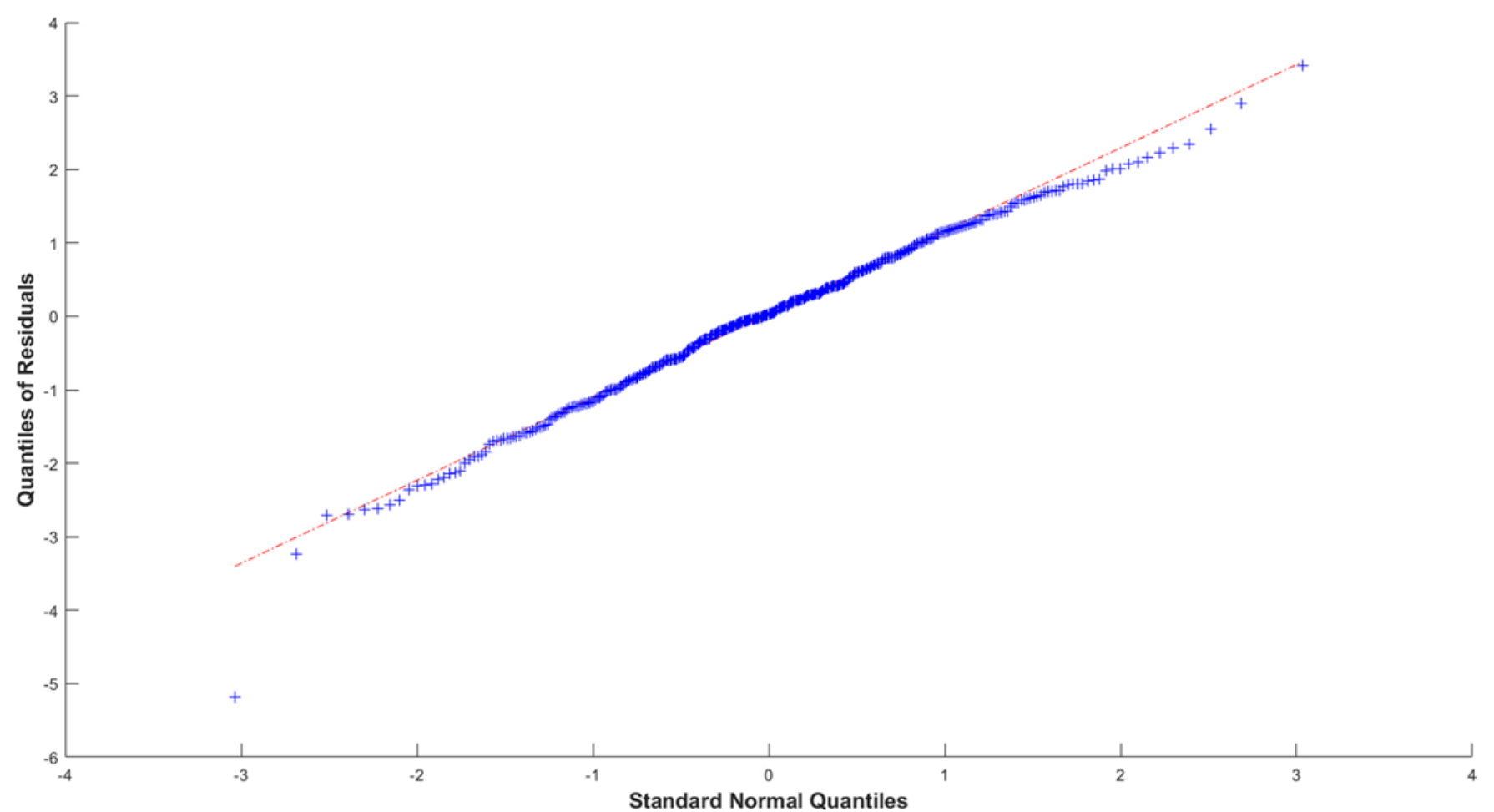

FIG. 5. Quantile-quantile plot of model residuals with normal distribution represented by the line. Figure is available in color online only.

assessment did not solely inform the decision to obtain further imaging (Table 1). However, those patients who experienced HPC had a significantly lower admission GCS score, in addition to other injury severity scores (Table 2). Moreover, those patients with poor GCS scores (3-8) had significantly higher expansion rates (Table 3). Interestingly, on multivariate analysis, each point decrease in GCS score increases a patient's chance of hospice placement or death (Table 4), but GCS score was excluded in our model for predicting HPC in the acute period (Table 5). While our research found GCS scores to be a predictive factor for eventual patient outcome, it is clear that more research must be done to establish consensus on the relationship between GCS score and HPC in patients with tIPH.

Other injury scoring systems, such as the ISS, provide a global picture of the extent of a patient's injuries following trauma. In our model, a high ISS was significantly associated with HPC; thus, the greater extent of the injury the more likely a tIPH is to evolve (Table 2). Furthermore, the extent of the injury measured by such scoring systems is capable of predicting the odds of patient placement in hospice or death (Table 4) as well as the extent to which the contusion will expand in the acute setting (Table 5). Sanus et al. demonstrated that ISS was a predictive factor for eventual contusion expansion, which supports our findings, but there is a paucity of literature that examines the predictive effects of ISS on tIPH. ${ }^{38}$ Nevertheless, despite the complex nature of TBI, which involves several inflammatory processes and cascades leading to neuroinflammation, the evaluation of TBI in the context of systemic trauma, including significant blood loss, adjacent soft-tissue injury, and compounded activation of proinflammatory processes, can inform the clinician regarding the potential for HPC and overall prognosis. ${ }^{12,14,16,19,33}$

\section{Absolute Platelet Count, Platelet Transfusion, and INR}

Multiple studies have found that a low platelet count at presentation, as well as prior use of antiplatelet or anticoagulation therapy, can predict HPC. ${ }^{20,27,42}$ However, the effects of managing low platelets with transfusion have not been examined with relation to HPC or expansion rate. Patients in our study had an average absolute platelet count of $230.5 \times 10^{9} / \mathrm{L}$, while only $8.3 \%$ received a platelet transfusion. There was a significantly lower ( $p$ $=2.672 \times 10^{-7}$ ) absolute platelet count in those patients who received a platelet transfusion $\left(163.6 \times 10^{9} / \mathrm{L}\right)$ compared with those who did not undergo transfusion $(236.5$ $\left.\times 10^{9} / \mathrm{L}\right)$. Although there is no protocol for platelet transfusion with TBI at our institution, leaving this administration to physician discretion, a low absolute platelet count is significantly related to a transfusion of platelets. $\mathrm{Pa}-$ tients in our study who were on a regimen antiplatelet or anticoagulation therapy prior to presentation had a higher expansion rate (Table 2), as expected based on prior studies. Our analysis also shows that neither platelet administration nor initial INR were independently correlated with HPC, yet a lower absolute platelet count was correlated with HPC (Table 2). However, among patients with HPC, those who had an absolute platelet count lower than $150 \times$ $10^{9} / \mathrm{L}$, those who received platelet transfusions, and those who had a higher initial INR exhibited a faster rate of expansion (Table 3). Platelet administration is predictive of second scan size (Table 5) but is not predictive of clinical 
outcome or disposition (Table 4), a finding that is in line with prior studies. , $^{8,17,40}$

As posited by Washington et al., platelet transfusion during tIPH confers no clinical benefit due to the side effects of the intervention itself, such as trauma-related lung injury. Additionally, it is hypothesized that platelet transfusion, although intended to reverse pre-tIPH antiplatelet therapy, does not actually inhibit the effects of the antiplatelet activity and would require multiple transfusions to overwhelm those effects to provide any reversal. ${ }^{40}$ Therefore, given the current literature and our findings, platelet transfusion in the setting of tIPH may not provide any clinical or radiological benefit, while a lower absolute platelet count is associated with HPC and increased expansion rate.

\section{Blood Alcohol Level}

Ethanol has been widely recognized for its antiplatelet effects. Older studies point to the potentiating effects of ethanol on prostacyclins, which have inherent antiplatelet properties..$^{11,18,28,30}$ Newer molecular studies have identified impaired calcium entry into platelets as the mechanism by which ethanol prevents platelet aggregation, rendering them dysfunctional., ${ }^{9,26,34}$ For these reasons, the effects of ethanol on platelet function must be considered when patients present with clinically significant hemorrhage. Here, differences in the mean BAL did not reach significance in patients with HPC compared with those with no HPC (Table 2), although there was a nonsignificant correlation between higher BAL and hemorrhagic progression. Similarly, neither Oertel et al. nor Juratli et al. identified BAL as a predictor of HPC..$^{20,32}$ BAL has not yet been studied as a predictor of expansion rate or radiological outcomes. Our results demonstrate that a higher BAL is univariately correlated with an elevated expansion rate (Table 3) and, on multivariate analysis, is predictive of size on the second scan (Table 5). These findings are unsurprising, given the biochemical and molecular studies that describe the antiplatelet properties of ethanol.

\section{Additional Intracranial Trauma}

Multiple other studies have demonstrated a correlation between HPC and additional intracranial hemorrhages, such as SAH, SDH, and EDH. Alahmadi et al. demonstrated that the presence of coexisting SDH was a significant predictor for contusion progression, while Juratli et al. reported that worsening prognosis was found among patients with acute SDH., ${ }^{1,20}$ In addition, Chang et al. demonstrated that HPC was independently associated with the presence of SAH and SDH. Furthermore, they presented a statistically significant association between tIPH growth and the presence of additional hemorrhage subtypes. ${ }^{7}$ On univariate analysis, there was a statistically significant relationship between HPC and the presence of SDH. Multivariate analysis did not establish that presence of any additional type of hemorrhage was predictive of patient outcome; however, the presence of EDH and SAH were both independently predictive of tIPH volume on the second scan. While the literature presents a fairly clear consensus that the presence of additional hemorrhage subtypes is correlated with HPC and worsened patient outcomes, there is no clear single category of hemorrhage that appears significantly more predictive than others.

\section{Craniotomy and Craniectomy}

Previous multivariate analysis has demonstrated a positive association with decompressive craniotomy and the likelihood of HPC. Cepeda and colleagues hypothesized that this is due to the tamponade effect of removing a bone flap. ${ }^{6}$ In contrast, our univariate analysis showed no significant relationship between craniotomy or craniectomy and tIPH volume on follow-up HCT (Table 2) or expansion rate (Table 3). Our multivariate analysis removed decompressive craniotomy or craniectomy from consideration, as it had little independent predictive value for disposition (Table 4) or size of tIPH on follow-up CT (Table 5). This is likely due to the small number of patients $(n=37)$ who underwent this procedure in our study population.

\section{Ventriculostomy}

There is a dearth of multivariate analysis on the effects of ventriculostomy on HPC or dispositions in the literature. Our univariate analysis did not show a significant association between ventriculostomy and tIPH volume on follow-up CT (Table 2) but showed a significant positive relationship between ventriculostomy and tIPH expansion rate (Table 3). Our multivariate analysis showed a positive association between use of ventriculostomy and odds of a death or hospice disposition (Table 4) as well as use of ventriculostomy and size of tIPH on follow-up CT (Table 5 ). We believe this is likely due to endogenous factors not captured by our data set. Patients underwent ventriculostomy likely on the basis of other clinical criteria associated with worse outcomes.

\section{Strengths and Limitations}

Our study has several limitations regarding its ability to identify variables that affect HPC, predict patient outcome, and predict the volumetric expansion after tIPH. First, this is a retrospective study with a narrow follow-up period limited to the disposition of the current hospitalization. Without long-term follow-up data, we are unable to assess the functional outcome, in addition to the morbidity and mortality, of TBI after the acute period. Furthermore, due to incomplete data collection on admission, 69 of the 491 patients had to be excluded from all multivariate analyses due to missing prehospital and/or in-hospital characteristics. Second, there is a selection bias of those patients with 2 scans, both admission and follow-up HCT sessions. Third, various unknown confounding factors from a patient's medical history, such as the use of illicit substances, previous TBI, or a history of congenital clotting disorders, could potentially lead to HPC and were not included in our analysis. Finally, there is no formal protocol for the transfusion of platelets with TBI at our institution, leaving their administration to physician discretion. Despite these limitations, our study volumetrically examines a large and diverse patient population from a level 1 trauma center. Like other studies examining HPC, we identified various factors that contribute to this expansion; however, we also investigated how these clinical factors relate to the rate of 
contusion expansion and the disposition of patients following TBI.

Furthermore, rather than a rudimentary cross-sectional measurement, our 3D volumetric measurements of hemorrhages sought to evaluate HPC in a more quantitative manner than previously attempted. Cutoffs for HPC used in prior works include $+0 \%,{ }^{7}+25 \%,{ }^{32,42}+30 \%,{ }^{6}$ and $+33 \% .^{2,41}$ Oertel et al. and Yuan et al. looked for progression along any one dimension. ${ }^{32,42}$ Chang, Cepeda, White, and Allison and their coauthors calculated intraparenchymal volumes using $(\mathrm{A} \times \mathrm{B} \times \mathrm{C}) / 2 .^{2,6,7,41}$ Conservative cutoffs (i.e., $>+0 \%$ ) are often employed to account for differences in patient placement that could affect the lengths used in the volume calculation. In contrast, our methodology sums the exact cross-sectional volumes, and thus our numbers would not be affected by the particular image slice selection or presence of nonellipsoid hemorrhages.

\section{Conclusions}

TBI, including tIPH, remains a significant worldwide cause of morbidity and mortality. Unique to tIPH, these traumatic lesions can progress over time and cause a mass effect on various structures, thereby resulting in severe and debilitating injury. The results presented provide further evidence that particular variables (age, injury severity, GCS score, BAL, concomitant SDH) are present in the expanding-hemorrhage population, while similar patient characteristics (i.e., age, GCS score, BAL, INR, platelet transfusion, anticoagulant/antiplatelet medication, initial hemorrhage volume, and ventriculostomy) individually contribute to the rate at which traumatic cerebral contusions blossom over an acute time course. Furthermore, we employed retrospective data to predict patient outcome and the acute volumetric expansion after tIPH, given a patient's prehospital and in-hospital characteristics. Understanding the relationship of these characteristics of the presenting patient can help predict the rate of expansion and highlight potential therapeutic interventions to improve TBI-associated morbidity and mortality.

\section{Acknowledgments}

We acknowledge the HI-RES imaging laboratory, trauma department, and emergency department at the Rhode Island Hospital.

\section{References}

1. Alahmadi H, Vachhrajani S, Cusimano MD: The natural history of brain contusion: an analysis of radiological and clinical progression. J Neurosurg 112:1139-1145, 2010

2. Allison RZ, Nakagawa K, Hayashi M, Donovan DJ, Koenig MA: Derivation of a predictive score for hemorrhagic progression of cerebral contusions in moderate and severe traumatic brain injury. Neurocrit Care 26:80-86, 2017

3. Bullock MR, Povlishock JT: Editor's commentary, in Guidelines for the Management of Severe Traumatic Brain Injury, ed 3. New York: Mary Ann Liebert, 2007

4. Bullock R, Golek J, Blake G: Traumatic intracerebral hematoma-which patients should undergo surgical evacuation? CT scan features and ICP monitoring as a basis for decision making. Surg Neurol 32:181-187, 1989
5. Carnevale J, Segar DJ, Drapcho B, Doberstein C, Morrison JF, Asaad W: Cerebral contusions: catalysts and counteractants. Neurosurgery 63 (Suppl 1):195-195, 2016 (Abstract 326)

6. Cepeda S, Gómez PA, Castaño-Leon AM, Martínez-Pérez R, Munarriz PM, Lagares A: Traumatic intracerebral hemorrhage: risk factors associated with progression. J Neurotrauma 32:1246-1253, 2015

7. Chang EF, Meeker M, Holland MC: Acute traumatic intraparenchymal hemorrhage: risk factors for progression in the early post-injury period. Neurosurgery 58:647-656, 2006

8. Creutzfeldt CJ, Weinstein JR, Longstreth WT Jr, Becker KJ, McPharlin TO, Tirschwell DL: Prior antiplatelet therapy, platelet infusion therapy, and outcome after intracerebral hemorrhage. J Stroke Cerebrovasc Dis 18:221-228, 2009

9. Ehrlich D, Humpel C: Effects of ethanol on aggregation, serotonin release, and amyloid precursor protein processing in rat and human platelets. Platelets 25:16-22, 2014

10. Faul M, Xu L, Wald MM, Coronado VG: Traumatic Brain Injury in the United States. Emergency Department Visits, Hospitalizations and Deaths 2002-2006. Atlanta: Centers for Disease Control and Prevention, 2010

11. Flamm ES, Demopoulos HB, Seligman ML, Tomasula JJ, De Crescito V, Ransohoff J: Ethanol potentiation of central nervous system trauma. J Neurosurg 46:328-335, 1977

12. Flierl MA, Stoneback JW, Beauchamp KM, Hak DJ, Morgan SJ, Smith WR, et al: Femur shaft fracture fixation in headinjured patients: when is the right time? J Orthop Trauma 24:107-114, 2010

13. Folkerson LE, Sloan D, Cotton BA, Holcomb JB, Tomasek JS, Wade CE: Predicting progressive hemorrhagic injury from isolated traumatic brain injury and coagulation. Surgery 158:655-661, 2015

14. Giannoudis PV, Veysi VT, Pape HC, Krettek C, Smith MR: When should we operate on major fractures in patients with severe head injuries? Am J Surg 183:261-267, 2002

15. Graham DI, Adams JH, Nicoll JA, Maxwell WL, Gennarelli TA: The nature, distribution and causes of traumatic brain injury. Brain Pathol 5:397-406, 1995

16. Grotz MR, Giannoudis PV, Pape HC, Allami MK, Dinopoulos H, Krettek C: Traumatic brain injury and stabilisation of long bone fractures: an update. Injury 35:1077-1086, 2004

17. Ivascu FA, Howells GA, Junn FS, Bair HA, Bendick PJ, Janczyk RJ: Predictors of mortality in trauma patients with intracranial hemorrhage on preinjury aspirin or clopidogrel. J Trauma 65:785-788, 2008

18. Jakubowski JA, Vaillancourt R, Deykin D: Interaction of ethanol, prostacyclin, and aspirin in determining human platelet reactivity in vitro. Arteriosclerosis 8:436-441, 1988

19. Jamjoom BA, Jamjoom AB: Timing of long bone fracture fixation in severe traumatic brain injury. Neurosciences (Riyadh) 17:111-114, 2012

20. Juratli TA, Zang B, Litz RJ, Sitoci KH, Aschenbrenner U, Gottschlich B, et al: Early hemorrhagic progression of traumatic brain contusions: frequency, correlation with coagulation disorders, and patient outcome: a prospective study. $\mathbf{J}$ Neurotrauma 31:1521-1527, 2014

21. Kim H, Jin ST, Kim YW, Kim SR, Park IS, Jo KW: Risk factors for early hemorrhagic progression after traumatic brain injury: a focus on lipid profile. J Neurotrauma 32:950-955, 2015

22. Kurland D, Hong C, Aarabi B, Gerzanich V, Simard JM: Hemorrhagic progression of a contusion after traumatic brain injury: a review. J Neurotrauma 29:19-31, 2012

23. Langlois JA, Rutland-Brown W, Wald MM: The epidemiology and impact of traumatic brain injury: a brief overview. $\mathbf{J}$ Head Trauma Rehabil 21:375-378, 2006

24. Lobato RD, Cordobes F, Rivas JJ, de la Fuente M, Montero A, Barcena A, et al: Outcome from severe head injury related 
to the type of intracranial lesion. A computerized tomography study. J Neurosurg 59:762-774, 1983

25. Lobato RD, Gomez PA, Alday R, Rivas JJ, Dominguez J, Cabrera A, et al: Sequential computerized tomography changes and related final outcome in severe head injury patients. Acta Neurochir (Wien) 139:385-391, 1997

26. Marumo M, Wakabayashi I: Diverse effects of ethanol on $\mathrm{Ca}^{2+}$ entry and subsequent aggregation of platelets. Alcohol 44:343-350, 2010

27. McMillian WD, Rogers FB: Management of prehospital antiplatelet and anticoagulant therapy in traumatic head injury: a review. J Trauma 66:942-950, 2009

28. Mehta P, Mehta J, Lawson D, Patel S: Ethanol stimulates prostacyclin biosynthesis by human neutrophils and potentiates anti-platelet aggregatory effects of prostacyclin. Thromb Res 48:653-661, 1987

29. Mendelow AD, Gregson BA, Rowan EN, Francis R, McColl E, McNamee P, et al: Early surgery versus initial conservative treatment in patients with traumatic intracerebral hemorrhage (STITCH[Trauma]): the first randomized trial. J Neurotrauma 32:1312-1323, 2015

30. Mikhailidis DP, Barradas MA, Jeremy JY: The effect of ethanol on platelet function and vascular prostanoids. Alcohol 7:171-180, 1990

31. National Center for Injury Prevention and Control: Report to Congress on Mild Traumatic Brain Injury in the United States: Steps to Prevent a Serious Public Health Problem. Atlanta: Centers for Disease Control and Prevention, 2003

32. Oertel M, Kelly DF, McArthur D, Boscardin WJ, Glenn TC, Lee JH, et al: Progressive hemorrhage after head trauma: predictors and consequences of the evolving injury. J Neurosurg 96:109-116, 2002

33. Pape HC, Tornetta P III, Tarkin I, Tzioupis C, Sabeson V, Olson SA: Timing of fracture fixation in multitrauma patients: the role of early total care and damage control surgery. J Am Acad Orthop Surg 17:541-549, 2009

34. Rosado JA, Nuñez AM, Lopez JJ, Pariente JA, Salido GM: Intracellular $\mathrm{Ca}^{2+}$ homeostasis and aggregation in platelets are impaired by ethanol through the generation of $\mathrm{H} 2 \mathrm{O} 2$ and oxidation of sulphydryl groups. Arch Biochem Biophys 452:9-16, 2006

35. Rundhaug NP, Moen KG, Skandsen T, Schirmer-Mikalsen K, Lund SB, Hara S, et al: Moderate and severe traumatic brain injury: effect of blood alcohol concentration on Glasgow Coma Scale score and relation to computed tomography findings. J Neurosurg 122:211-218, 2015

36. Rutland-Brown W, Langlois JA, Thomas KE, Xi YL: Incidence of traumatic brain injury in the United States, 2003. J Head Trauma Rehabil 21:544-548, 2006

37. Saatman KE, Duhaime AC, Bullock R, Maas AI, Valadka A, Manley GT: Classification of traumatic brain injury for targeted therapies. J Neurotrauma 25:719-738, 2008

38. Sanus GZ, Tanriverdi T, Alver I, Aydin S, Uzan M: Evolving traumatic brain lesions: predictors and results of ninety-eight head-injured patients. Neurosurg Q 14:97-104, 2004
39. Servadei F, Nanni A, Nasi MT, Zappi D, Vergoni G, Giuliani $\mathrm{G}$, et al: Evolving brain lesions in the first 12 hours after head injury: analysis of 37 comatose patients. Neurosurgery 37:899-907, 1995

40. Washington CW, Schuerer DJ, Grubb RL Jr: Platelet transfusion: an unnecessary risk for mild traumatic brain injury patients on antiplatelet therapy. J Trauma 71:358-363, 2011

41. White CL, Griffith S, Caron JL: Early progression of traumatic cerebral contusions: characterization and risk factors. $\mathbf{J}$ Trauma 67:508-515, 2009

42. Yuan F, Ding J, Chen H, Guo Y, Wang G, Gao WW, et al: Predicting progressive hemorrhagic injury after traumatic brain injury: derivation and validation of a risk score based on admission characteristics. J Neurotrauma 29:2137-2142, 2012

\section{Disclosures}

The authors report no conflict of interest concerning the materials or methods used in this study or the findings specified in this paper.

\section{Author Contributions}

Conception and design: Carnevale, Segar, Powers, Shah, Morrison, Asaad. Acquisition of data: Carnevale, Segar, Powers, Doberstein, Drapcho, Williams, Collins. Analysis and interpretation of data: Carnevale, Segar, Powers, Shah, Doberstein, Drapcho, Williams, Asaad. Drafting the article: Carnevale, Powers, Shah, Doberstein, Drapcho. Critically revising the article: Carnevale, Segar, Powers, Doberstein, Morrison, Collins, Monteiro, Asaad. Reviewed submitted version of manuscript: all authors. Approved the final version of the manuscript on behalf of all authors: Carnevale. Statistical analysis: Carnevale, Segar, Powers, Shah, Monteiro, Asaad. Administrative/technical/material support: Carnevale. Study supervision: Carnevale, Asaad.

\section{Supplemental Information \\ Previous Presentations}

Portions of this work were presented in abstract/poster/oral form at the 83rd AANS Annual Scientific Meeting, May 2-6, 2015, Washington, DC; 2015 AMA Research Symposium, November 13, 2015, Atlanta, Georgia; Brain Science Day, Brown University, March 30, 2016, Providence, Rhode Island; 84th AANS Annual Scientific Meeting, April 30-May 4, 2016, Chicago, Illinois; 2016 CNS Annual Meeting, September 24-28, 2006, San Diego, California; and 2017 CNS Annual Meeting, October 7-11, 2017, Boston, Massachusetts.

\section{Correspondence}

Joseph A. Carnevale: NewYork-Presbyterian Hospital/Weill Cornell Medicine, Brain \& Spine Center, New York, NY. joseph_ carnevale@alumni.brown.edu. 